\section{Ansofaxine Hydrochloride}

Ansofaxine hydrochloride (LY03005; LPM570065) is a triple reuptake inhibitor that inhibits serotonin, dopamine and norepinephrine reuptake. This novel triple reuptake inhibitor is a carboxylic acid ester prodrug of desvenlafaxine. It is currently under development by Luye Pharma Group for the treatment of major depressive disorder - a frequent and heterogeneous disorder induced by a complex pattern of genetic, epigenetic, developmental, and environmental factors [1-3].

Pathophysiology of depression has been researched for decades with the aim of producing adequate pharmacotherapy. Today's conventional antidepressants, such as selective serotonin reuptake inhibitors (SSRI's) and serotonin and norepinephrine reuptake inhibitors (SNRI's) involve inhibiting serotonin and noradrenaline uptake from the synapse. Those mechanisms of action are congruent with the monoamine hypothesis of depression [4]. The aforementioned molecules are known to be effective, but they typically have been plagued by anhedonia, sexual dysfunction and inability to improve cognitive impairment. The listed symptomatology could be reduced by enhancing the dopamine neurotransmission. Additionally, the onset of therapeutic action is delayed by several weeks, which as well acts as a limitation in therapeutic efficacy [5].

In a study by Zhang and associates, ansofaxine was shown to penetrate the rat striatum, then convert into desvenlafaxine and manifest elevated total exposure collated with the administration of desvenlafaxine. Better penetration could be explained by slight solubility in water and enhanced lipophilicity towards desvenlafaxine, which help desvenlafaxine to overcome obstacles of drug delivery in vivo. Acute and chronic administration of oral suspension of ansofaxine increases the serotonin, dopamine and norepinephrine concentration more than the relative administration of desvenlafaxine. Desvenlafaxine has in vitro IC50 values of $53 \mathrm{nM}$ and 538 $\mathrm{nM}$ for inhibition of serotonin and norepinephrine reuptake, while ansofaxine has in vitro IC50 values of $723 \mathrm{nM}, 763 \mathrm{nM}$, and $491 \mathrm{nM}$ for serotonin, norepinephrine, and dopamine reuptake inhibition. Ansofaxine demonstrated better antidepressant-like activity in the forced swim test (used to measure the depression-like behaviour in rats) after 


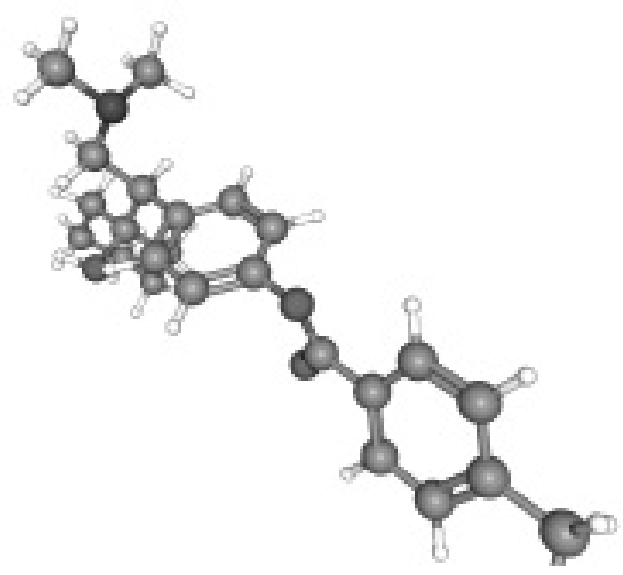

Figure 1. The chemical structure of LPM570065.

acute and chronic administration compared with desvenlafaxine. Ansofaxine also attenuated the harmful effects of the excessive activation of inhibitory $5-\mathrm{HT}_{1 \mathrm{~A}}$ autoreceptors induced by desvenlafaxine. Those effects are linked to the fact that it takes several weeks to produce the antidepressant effect for patients treated with a SSRI or SNRI. Namely, the acute elevation of serotonin levels produced by SSRI and SNRI activates $5-\mathrm{HT}_{1 \mathrm{~A}}$ autoreceptors and leads to restrained firing rates in serotonergic neurons. It is important to emphasize that, compared with desvenlafaxine, ansofaxine also might contribute to the enhancing of dopamine neurochemical activity which could lead to aforementioned reduction of anhedonia, sexual dysfunction and cognitive impairment. Enhancing dopaminergic neurotransmission could as well counter the repercussions on $5-\mathrm{HT}_{1 \mathrm{~A}}$ autoreceptors. In all probability, the elevation of extracellular dopamine levels could activate $\mathrm{D}_{2}$ receptors which would then lead to indirect attenuation of the excessive activation of inhibitory 5-HT ${ }_{1 \mathrm{~A}}$ autoreceptors [3].
Luye Pharma Group commenced ansofaxine hydrochloride extended release Phase I healthy volunteer study in Japan at the end of 2019 [1]. Apart from Japan, the Group is executing LY03005 Phase II clinical trial in China for Ansofaxine Hydrochloride extended release tablets [6]. As of March 2020, the U.S. Food and Drug administration (FDA) has accepted the filing of a New Drug Application for LY03005 [7].

All in all, LY03005 is anticipated to aid the preservation of patients' sexual function, to manifest a better safety profile with more rapid onset and higher efficacy, consequently providing better options in treatment [8]. Research so far indicates that this new molecule could be a promising candidate for depression treatment because of its comprehensive targeting of the monoamine system.

Assistant Professor Vjekoslav Peitl, MD, PhD

Darko Vlahović, $M D$ 


\section{References}

1. Marketscreener. Luye Pharma: Voluntary Announcement-Ansofaxine Hydrochloride extended release tablets commenced (LY03005) commenced phase I healthy volunteer study in Japan [Internet]. 2020 [cited November $1^{\text {st }}$ 2020]. Available from: https://www.marketscreener.com/quote/stock/ LUYE-PHARMA-GROUP-LTD-16860092/ news / Luye-Pharma-VOLUNTARY-ANNOUNCEMENT-ANSOFAXINE-HYDROCHLORIDE-EXTENDED-RELEASE-TABLETS-LY03005-C-29718982/

2. Hasler G, Drevets WC, Manji HK, Charney DS. Discovering endophenotypes for major depression. Neuropsychopharmacol. 2004;29:1765-81.

3. Zhang R, Li X, Shi Y, Shao Y, Sun K, Wang A, et al. The effects of LPM570065, a novel triple reuptake inhibitor, on extracellular serotonin, dopamine and norepinephrine levels in rats. PLoS One. 2014;9:e91775.

4. Belmaker R, Agam G. Major depressive disorder. New Engl J Med. 2008;358:55-68.
5. Stahl SM. Stahlovi temelji psihofarmakologije. Jastrebarsko: Naklada Slap; 2017.

6. Reuters. Brief Luye pharma updates on development [Internet]. 2020 [cited November $1^{\text {st }} 2020$ ]. Available from: https://br.reuters.com/article/ brief-luye-pharma-updates-on-development/ brief-luye-pharma-updates-on-development-ofansofaxine-hydrochloride-extended-release-tablets-idINFWN1PI0OU

7. Luye Pharma. NDA Filing for Luye Pharma's Antidepressant Drug LY03005 Accepted by the U.S. FDA [Internet]. 2020 [cited November $1^{\text {st }} 2020$ ]. Available from: https://www.luye.cn/lvye_en/ view.php?id=1809

8. Luye pharma. Luye Pharma's Investigational Drug Ansofaxine Hydrochloride Extended Release Tablets to Start Clinical Trials in Japan [Internet]. 2020 [cited November $1^{\text {st }} 2020$ ]. Available from: https://www.luye.cn/lvye_en/view.php?id=1757 
